\title{
Caracterização de resíduo (lodo) proveniente de estação de tratamento de águas visando sua utilização em cerâmica vermelha
}

\section{(Characterization of waterworks waste (sludge) aiming its use in red ceramic)}

\author{
E. M. S. Oliveira, S. Q. Machado, J. N. F. Holanda \\ CCT- LAMAV, Universidade Estadual do Norte Fluminense \\ Av. Alberto Lamego 2000, Campos dos Goytacazes, RJ 28013-602 \\ holanda@uenf.br
}

\begin{abstract}
Resumo
O presente trabalho teve como objetivo avaliar o resíduo (lodo) gerado por Estação de Tratamento de Águas (ETA) da região de Campos dos Goytacazes-RJ. Com essa meta foram estudadas as características mineralógica e físico-químicas do resíduo de ETA, visando seu aproveitamento como matéria-prima na indústria de cerâmica vermelha. Consta do estudo uma série de ensaios de caracterização tais como análise química, difração de raios X, análise termogravimétrica e térmica diferencial, análise morfológica, granulometria, capacidade de troca catiônica e propriedades plásticas. Os resultados obtidos indicam claramente que o resíduo de ETA pode ser usado como constituinte de massa argilosa para fabricação de cerâmica vermelha.

Palavras-chave: resíduo de ETA, caracterização, reciclagem, cerâmica vermelha.
\end{abstract}

Abstract

The aim of this work was to evaluate the waste (sludge) from waterworks of the Campos dos Goytacazes-RJ region. With this in view, the mineralogical and physical-chemical characteristics of the waste materials were studied for their use as raw materials in the red ceramic industry. As part of the study, a series of characterization tests, such as chemical analysis, $X$-ray diffraction, thermal analysis, morphological analysis, particle size analysis, cation exchange capacity and plasticity were carried out. The results indicate clearly that the ETA waste has potential to be used as raw material for the manufacture of red ceramics.

Keywords: waterworks waste, characterization, recycling, red ceramic.

\section{INTRODUÇÃO}

A água, além de ser indispensável aos seres humanos, à flora e à fauna, apresenta do ponto de vista industrial uma larga variedade de aplicações tais como matéria-prima, solvente, fluido de refrigeração, meio de transporte, agente de limpeza, fonte de vapor, entre outros [1]. Praticamente todos os locais de captação de água estão fora dos padrões de potabilidade. Assim, torna-se indispensável o tratamento das águas para o consumo.

As Estações de Tratamento de Águas (ETA) têm grande importância econômica e social, bem como estão presentes em grande parte dos municípios brasileiros. As ETA basicamente removem o material em suspensão na água bruta, como por exemplo argilominerais, por tratamento químico usando floculantes, seguido por decantação e filtração [2]. Os floculantes mais empregados no tratamento primário de água são os sulfatos à base de alumínio e ferro. Esta atividade, no entanto, produz uma grande quantidade de resíduo (lodo). De um modo geral, as características do resíduo variam com a natureza da água bruta, dos processos unitários e dos produtos químicos aplicados. Considera-se basicamente como constituintes da água os sólidos suspensos originalmente contidos na fonte de água, acrescidos de produtos resultantes dos reagentes aplicados à água durante o tratamento. O destino deste tipo de resíduo tem sido no Brasil, ao longo dos anos, os sistemas hídricos mais próximos.

A ETA da região de Campos dos Goytacazes-RJ, que é responsável por cerca de $80 \%$ da água tratada do município, capta água na Bacia do Paraíba do Sul, gerando enorme quantidade de resíduo na forma de um lodo. Este resíduo vem sendo lançado no Rio Paraíba do Sul, contribuindo para seu assoreamento. Ressalta-se que esta situação de geração de resíduos em ETA com destino inadequado é encontrada em muitos municípios brasileiros. Portanto, tal problemática de resíduos de ETA e seu destino final adequado ao controle ambiental técnico-legal da atualidade, é uma questão a ser solucionada.

A indústria de cerâmica vermelha é altamente promissora para absorver resíduos poluentes [3-6]. Isto é decorrente principalmente do fato que as massas argilosas utilizadas são por natureza heterogêneas. As massas argilosas são materiais poliminerálicos constituídos de argilominerais (materiais plásticos) e minerais não argilosos (materiais não plásticos), 
com ampla variação mineralógica, física e química [7]. De forma que as massas argilosas para cerâmica vermelha são tolerantes e aceitam a presença de materiais residuais de diversos tipos e origens, mesmo quando adicionados em quantidades significantes.

A utilização de resíduo de ETA em cerâmica vermelha tem sido muito pouco estudada, apesar de sua importância ambiental e econômica. Recentemente, o resíduo da ETA de São Leopoldo-RS tem sido estudado visando seu aproveitamento cerâmico $[8,9]$. Os resultados mostraram que corpos cerâmicos contendo resíduo de ETA apresentaram propriedades tecnológicas adequadas para uso em cerâmica vermelha, dependendo da temperatura de queima.

O objetivo principal deste trabalho é a caracterização mineralógica e físico-química de uma amostra representativa do resíduo gerado na ETA do município de Campos dos Goytacazes, RJ. A possibilidade para aproveitamento em cerâmica vermelha é considerada. Para tal caracterização, é necessário usar os seguintes métodos de análises: fluorescência de raios $X$, difração de raios $X$, microscopia eletrônica de varredura, peneiramento/sedimentação e análise térmica.

\section{MATERIAIS E MÉTODOS}

No presente trabalho, o resíduo utilizado foi coletado na ETA de Campos dos Goytacazes, RJ. A amostra do resíduo natural (bruto) apresenta-se na forma de lodo. O resíduo foi então homogeneizado e submetido a processo de secagem em estufa por $24 \mathrm{~h}$. Em seguida o resíduo seco foi destorroado e peneirado para a fração $<40$ mesh (425 $\mu \mathrm{m})$, constituindo-se na amostra de trabalho. De forma, que daqui por diante o resíduo será denominado de resíduo de ETA.

A composição química da amostra do resíduo de ETA foi determinada por fluorescência de raios $\mathrm{X}$. A perda de massa da amostra calcinada num forno mufla a $1000{ }^{\circ} \mathrm{C}$ foi determinada de acordo com: $\% \mathrm{PF}=(\mathrm{A}-\mathrm{B}) / \mathrm{A} \times 100$, onde $\mathrm{A}$ é o peso da amostra seca em $110^{\circ} \mathrm{C}$ e B é o peso da amostra calcinada a $1000^{\circ} \mathrm{C}$ durante $1 \mathrm{~h}$.

A granulometria da amostra foi determinada por combinação de peneiramento e sedimentação de acordo com a norma NBR 7181-84. A massa específica real dos grãos foi determinada de acordo com a norma NBR 6508-84. Os limites de consistência de Atterberg foram determinados de acordo com as normas NBR 6459-84 e NBR 7180-84. A capacidade de troca catiônica, teor de matéria orgânica e teor de sais solúveis foram também determinados.

A análise mineralógica qualitativa foi feita por difração de raios X (Difratômetro URD 65, Seifert) usando radiação monocromática $\mathrm{Cu}-\mathrm{K}_{\alpha}$, sob ângulo $2 \theta$ de $5^{\circ}$ até $60^{\circ}$. Os experimentos de análise térmica (Analisador Simultâneo ATGATD, SDT 2960, TA Instruments) foram realizados sob atmosfera de ar da temperatura ambiente $\left(\cong 25^{\circ} \mathrm{C}\right)$ até $1150^{\circ} \mathrm{C}$, com uma taxa de aquecimento de $10^{\circ} \mathrm{C} / \mathrm{min}$.

A morfologia das partículas do resíduo de ETA foi analisada por microscopia eletrônica de varredura. Além disso, foi feito mapeamento de elementos por EDS.

\section{RESULTADOS E DISCUSSÃO}

O difratograma de raios $\mathrm{X}$ da amostra do resíduo de ETA estudado é mostrado na Fig. 1. Verificam-se picos de difração característicos das fases cristalinas referentes a caulinita $\left(\mathrm{Al}_{2} \mathrm{O}_{3} \cdot 2 \mathrm{SiO}_{2} \cdot 2 \mathrm{H}_{2} \mathrm{O}\right)$, sílica $\left(\mathrm{SiO}_{2}\right)$ e gibsita $\left(\mathrm{Al}(\mathrm{OH})_{3}\right)$. Ainda, há indícios da presença da mica moscovita detectada por seus picos menos intensos.

A Tabela I mostra os resultados da composição química da amostra do resíduo de ETA. Do ponto de vista químico, o resíduo é constituído basicamente por $\mathrm{SiO}_{2}, \mathrm{Al}_{2} \mathrm{O}_{3}$ e $\mathrm{Fe}_{2} \mathrm{O}_{3}$ que correspondem à cerca de $80,42 \%$. A perda ao fogo do resíduo de ETA é relativamente alta, da ordem de $16,93 \%$, que pode estar relacionada principalmente com a presença de argilominerais, hidróxidos e matéria orgânica. Os teores de

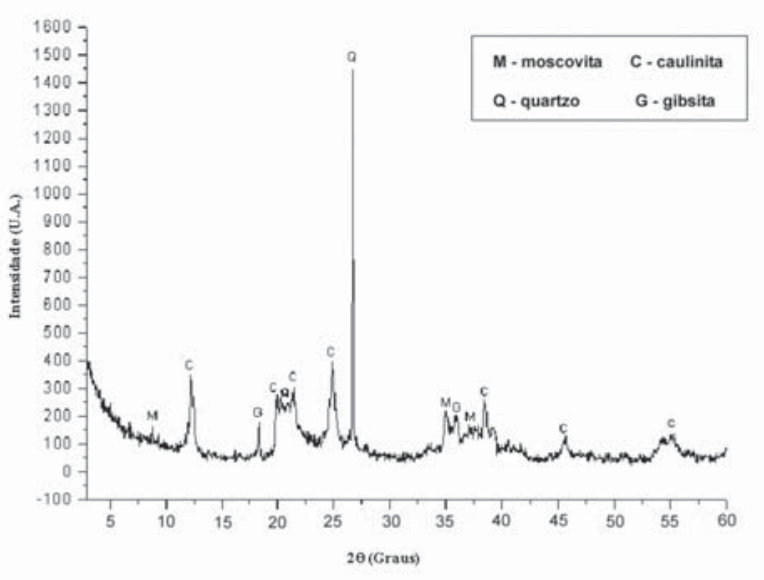

Figura 1: Difratograma de raios X do resíduo de ETA.

[Figure 1: X-ray diffraction pattern of the waterworks waste.]

Tabela I - Composição química do resíduo de ETA. [Table I - Chemical composition of the ETA waste.]

\begin{tabular}{cc}
\hline Composição & (\% em peso) \\
\hline $\mathrm{SiO}_{2}$ & 35,92 \\
\hline $\mathrm{Al}_{2} \mathrm{O}_{3}$ & 31,71 \\
\hline $\mathrm{Fe}_{2} \mathrm{O}_{3}$ & 12,79 \\
\hline $\mathrm{TiO}_{2}$ & 1,10 \\
\hline $\mathrm{MnO}$ & 0,09 \\
\hline $\mathrm{MgO}$ & 0,37 \\
\hline $\mathrm{CaO}$ & 0,10 \\
\hline $\mathrm{K}_{2} \mathrm{O}$ & 0,58 \\
\hline $\mathrm{Na}_{2} \mathrm{O}$ & 0,06 \\
\hline $\mathrm{P}_{2} \mathrm{O}_{5}$ & 0,35 \\
\hline $\mathrm{PF}$ & 16,93 \\
\hline
\end{tabular}

$P F=$ perda ao fogo 
óxidos alcalinos $\left(\mathrm{K}_{2} \mathrm{O}\right.$ e $\left.\mathrm{Na}_{2} \mathrm{O}\right)$ e alcalinos terrosos $(\mathrm{MgO}$ e $\mathrm{CaO}$ ) são baixos. Além disso, a composição química do resíduo de ETA é muito semelhante a algumas das argilas usadas no Polo Ceramista da região de Campos dos Goytacazes, RJ [10]. De fato, as argilas desta região são provenientes de sedimentos quaternários (recentes) originados de processos de decantação de material sílico-argiloso da carga de suspensão, após eventos de enchentes do Rio Paraíba do Sul [11].

A Tabela II apresenta algumas características importantes do resíduo de ETA. A capacidade de troca catiônica (CTC) do resíduo é da ordem de 9,85 meq/100 g. Este valor está dentro da faixa usual de valores de CTC para a caulinita (3 até 15 meq/100 g) [12]. Além disso, este valor é compatível com os valores de CTC das argilas cauliníticas da região de Campos dos Goytacazes-RJ (7,88 - 12,30 meq/100g) [13]. No caso da caulinita o processo de troca ocorre predominantemente nas faces dos cristais e deve-se principalmente as ligações quebradas. $\mathrm{O} \mathrm{pH}$ (em água) do resíduo pode ser considerado como sendo levemente ácido. Os resultados também mostram que o resíduo apresenta baixos valores de matéria orgânica $(0,95 \%)$, carbono orgânico $(0,55 \%)$ e sais solúveis (em água). Estes valores são adequados para utilização em cerâmica vermelha. Assim, o surgimento de defeitos como eflorescência e coração negro não devem ser esperados em produtos de cerâmica vermelha contendo resíduo de ETA. A matéria orgânica encontrada contribui para aumentar a plasticidade e a CTC do resíduo. Em geral a matéria orgânica ocorre em massas argilosas na forma de linhito, ceras e derivados de ácidos úmicos. A amostra do resíduo de ETA calcinada a $1000^{\circ} \mathrm{C}$ apresentou cor vermelha. Esta cor é típica dos produtos de cerâmica vermelha e deve-se ao alto conteúdo de $\mathrm{Fe}_{2} \mathrm{O}_{3}$, como mostrado na Tabela I.

O comportamento térmico (ATD/ATG/DTG) do resíduo de ETAé mostrado na Fig. 2. Conforme observado nesta figura,

Tabela II - Características do resíduo de ETA. [Table II - Characteristics of the ETA waste.].

\begin{tabular}{cc}
\hline CTC, meq/100 g & 9,85 \\
\hline $\mathrm{PH}\left(\mathrm{H}_{2} \mathrm{O}\right)$ & 6,0 \\
\hline Teor de matéria orgânica, $\%$ & 0,95 \\
\hline Teor de carbono orgânico, $\%$ & 0,55 \\
\hline Cor em $1000^{\circ} \mathrm{C}$ & Vermelha \\
\hline Teor de sais solúveis, ppm \\
\hline $\mathrm{K}$ & 1,9 \\
\hline $\mathrm{Ca}$ & 25,1 \\
\hline $\mathrm{Mg}$ & 28,0 \\
\hline $\mathrm{Al}$ & 0,0 \\
\hline $\mathrm{H}+\mathrm{Al}$ & 28,7 \\
\hline $\mathrm{Na}$ & 14,8 \\
\hline Teor de $\mathrm{S}-\mathrm{SO}{ }_{4}, \mathrm{ppm}$ & 68 \\
\hline
\end{tabular}

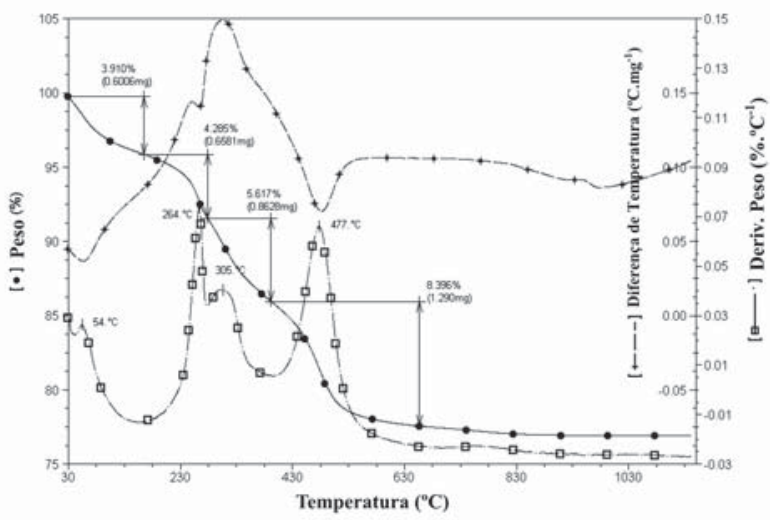

Figura 2: Curvas ATD/ATG/DTG do resíduo de ETA.

[Figure 2: DTA/TGA/TGD curves of the waterworks water.]

existem quatro eventos térmicos em $54{ }^{\circ} \mathrm{C}, 264{ }^{\circ} \mathrm{C}, 305^{\circ} \mathrm{C}$ e $477^{\circ} \mathrm{C}$, acompanhados por uma significativa perda de massa (medida TG) na amostra do resíduo estudado.

O primeiro evento corresponde a remoção de água fisicamente adsorvida típico de materiais argilosos. O resíduo de ETA é rico em caulinita (Fig. 1). O segundo evento térmico em $264{ }^{\circ} \mathrm{C}$ está provavelmente relacionado a dehidratação de hidróxidos existentes, tais como gibsita e goetita. Em torno de $305{ }^{\circ} \mathrm{C}$ foi observado um evento térmico acompanhado por perda de massa da ordem de 5,62\%. Este evento pode estar relacionado a decomposição de matéria orgânica. Ainda, pode estar também associado a presença de sulfatos, como por exemplo sulfato de alumínio, utilizado como floculante no processo de tratamento de águas [2]. O sulfato de alumínio perde água quimicamente ligada por volta de $300{ }^{\circ} \mathrm{C}$ [14]. Contudo, a inexistência de uma linha base dificulta muito a interpretação deste fenômeno térmico, possibilitando apenas a sua especulação. A própria existência de dois fenômenos térmicos próximos, no caso em $264^{\circ} \mathrm{C}$ e $305^{\circ} \mathrm{C}$, pode estar contribuindo para isso. A natureza mais larga do pico em 305 ${ }^{\circ} \mathrm{C}$ é outro fator a ser considerado, já que fenômenos superpostos podem estar ocorrendo. $\mathrm{O}$ vale endotérmico na temperatura de $477{ }^{\circ} \mathrm{C}$ está associado principalmente a desidroxilação da caulinita, levando a formação de metacaulinita.

Um pequeno pico exotérmico foi observado em torno de $960^{\circ} \mathrm{C}$, o qual não está associado a qualquer perda de massa. Este pico deve-se fundamentalmente a quebra da estrutura da metacaulinita para a formação de novas fases cristalinas tais como $\gamma-\mathrm{Al}_{2} \mathrm{O}_{3}$ e/ou mulita primária [12].

Os eventos endotérmicos são acompanhados por um intenso processo de transferência de massa na amostra, como mostrado nas curvas TG/DTG e resumidos na Tabela III. A amostra apresentou uma perda de massa total obtida da curva TG da ordem de 22,2\% durante o aquecimento, enquanto que o valor da perda ao fogo foi de $16,93 \%$ (Tabela I). A diferença observada está relacionada ao fato que a perda ao fogo foi determinada com a amostra seca a $110^{\circ} \mathrm{C}$, enquanto que a medida de TG foi obtida a partir da temperatura ambiente em torno de $25^{\circ} \mathrm{C}$. 
Tabela III - Resultados de TG/DTG do resíduo de ETA. [Table III - TG/DTG results of ETA waste.]

\begin{tabular}{cc}
\hline $\begin{array}{c}\text { Perda de } \\
\text { Massa } \\
(\mathrm{TG} / \%)\end{array}$ & $\begin{array}{c}\text { DTG máx. } \\
\left(\%{ }^{\circ} \mathrm{C}^{-1}\right)\end{array}$ \\
\hline 3,9 & 54 \\
\hline 4,3 & 204 \\
\hline 5,6 & 305 \\
\hline 8,4 & 477 \\
\hline
\end{tabular}

A curva granulométrica do resíduo de ETA é mostrada na Fig. 3. O resíduo apresenta uma larga distribuição de tamanho de partícula compreendida na faixa de 1 até $425 \mu \mathrm{m}$. Verificase que o resíduo apresenta alto teor de partículas ( $\cong 45 \%)$ abaixo de $2 \mu \mathrm{m}$. Este tamanho de partícula corresponde a fração argila em algumas escalas internacionais para classificação de solos [12]. Além disso, esta fração está fundamentalmente relacionada a presença de argilominerais, como por exemplo a caulinita, como comprovado pelos dados de DRX (Fig.1). O conteúdo de silte $(2 \leq \mathrm{x}<60 \mu \mathrm{m})$ é da ordem de $41 \%$, enquanto que o conteúdo da fração areia $(60 \leq x<600 \mu \mathrm{m})$ é de cerca de $14 \%$.

Os dados granulométricos do resíduo de ETA foram localizados no Diagrama de Winkler [15], como mostrado na Fig. 4. Este diagrama ternário é baseado sobre o tamanho de partículas das formulações argilosas, onde os vértices representam diferentes faixas de tamanhos $(<2 \mu \mathrm{m} ; 2-20 \mu \mathrm{m}$; $>20 \mu \mathrm{m}$ ). Além do mais, este diagrama mostra as regiões mais adequadas do ponto de vista granulométrico para obtenção de produtos de cerâmica vermelha. Estas regiões são: região A material de qualidade; região $\mathrm{B}$ - telhas; região C - tijolos furados; e região D - tijolos maciços. Os produtos de maior qualidade necessitam de uma massa argilosa rica na fração < $2 \mu \mathrm{m}$. No entanto, em todos os casos a presença de material não plástico (> $20 \mu \mathrm{m}$ ) em quantidades adequadas é essencial. Os materiais não plásticos são responsáveis pela menor

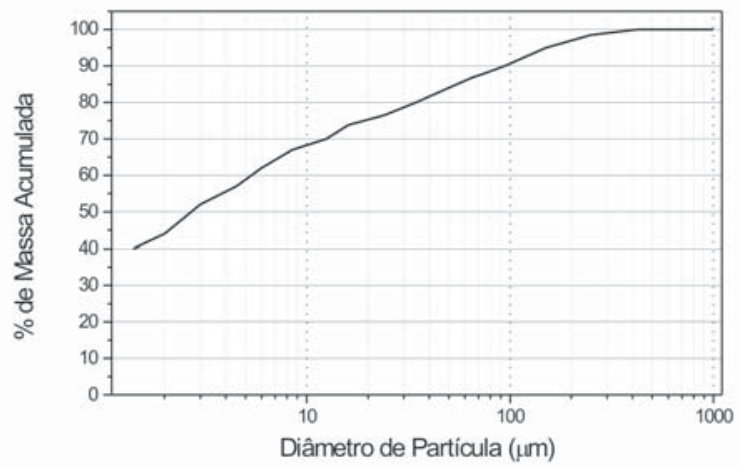

Figura 3: Curva granulométrica do resíduo de ETA. [Figure 3: Granulometric curve of the waterworks waste.]

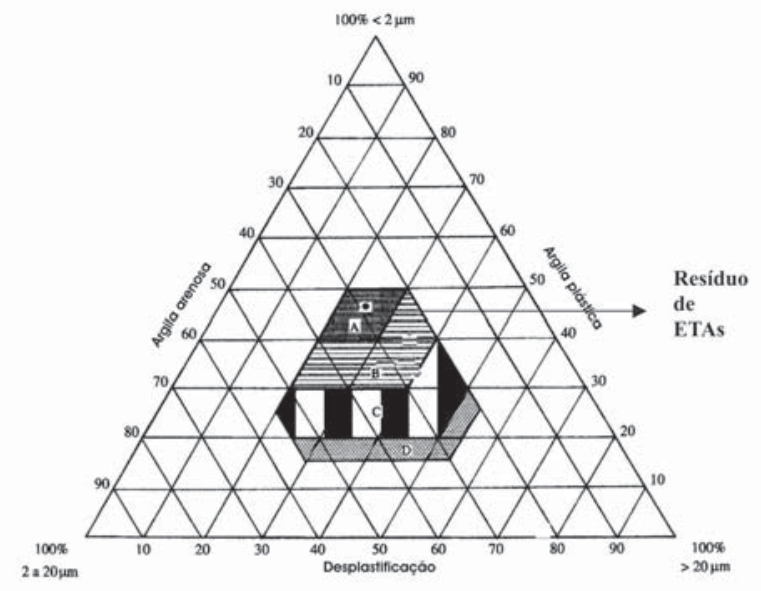

Figura 4: Classificação granulométrica para a amostra do resíduo de ETA de acordo com o diagrama de Winkler.

[Figure 4: Granulometric classification for the waterworks waste sample according to Winkler diagram.]

plasticidade da massa argilosa e retração dimensional durante o processo de fabricação. Os resultados mostram claramente que o resíduo de ETA localiza-se numa região apropriada para fabricação de produtos cerâmicos de alta qualidade. Este resultado é muito importante por mostrar que o resíduo de ETA estudado, por sua própria natureza, pode ser considerado como uma formulação de massa argilosa natural com grande potencial de uso na indústria de cerâmica vermelha.

A Fig. 5 mostra os aspectos morfológicos e o espectro de EDS obtidos para o resíduo de ETA estudado. O resíduo de ETA é constituído de placas de lamelas com perfil irregular. Existe uma grande quantidade de placas $<2 \mu \mathrm{m}$, provavelmente de caulinita. É observada também a larga distribuição de tamanho de partículas do resíduo, corroborando os dados granulométricos da Fig. 3. O mapeamento por elementos através de EDS indicou a presença de $\mathrm{Si}, \mathrm{Al}, \mathrm{Fe}$ e Ti, os quais ratificam os dados de composição química (Tabela I). Detalhes das placas aglomeradas do resíduo de ETA são mostrados na Fig. 6. Na Fig. 7 é mostrada uma partícula fragmentada constituinte do resíduo, provavelmente de uma carapaça de diatomácea com formato navicular [16].

A Tabela IV mostra a massa específica real e a plasticidade do resíduo de ETA. O resíduo de ETA apresentou um valor de massa específica real (MER) da ordem de 2,63 g/ $\mathrm{cm}^{3}$, o qual está dentro da faixa para materiais argilosos. De fato tem sido mostrado na literatura [13] que as argilas cauliníticas da região de Campos dos Goytacazes-RJ apresentam valores de MER compreendidos entre $2,55-2,77 \mathrm{~g} / \mathrm{cm}^{3}$.

A determinação da plasticidade do resíduo de ETA é de grande importância para a sua aplicação prática em cerâmica vermelha. Do ponto de vista da tecnologia cerâmica [12, 17], o termo plasticidade está relacionado à propriedade de uma massa argilosa de mudar a sua forma sem ruptura, sob a ação de uma força externa, bem como a retenção da nova forma após retirada da força aplicada. A plasticidade de massas 

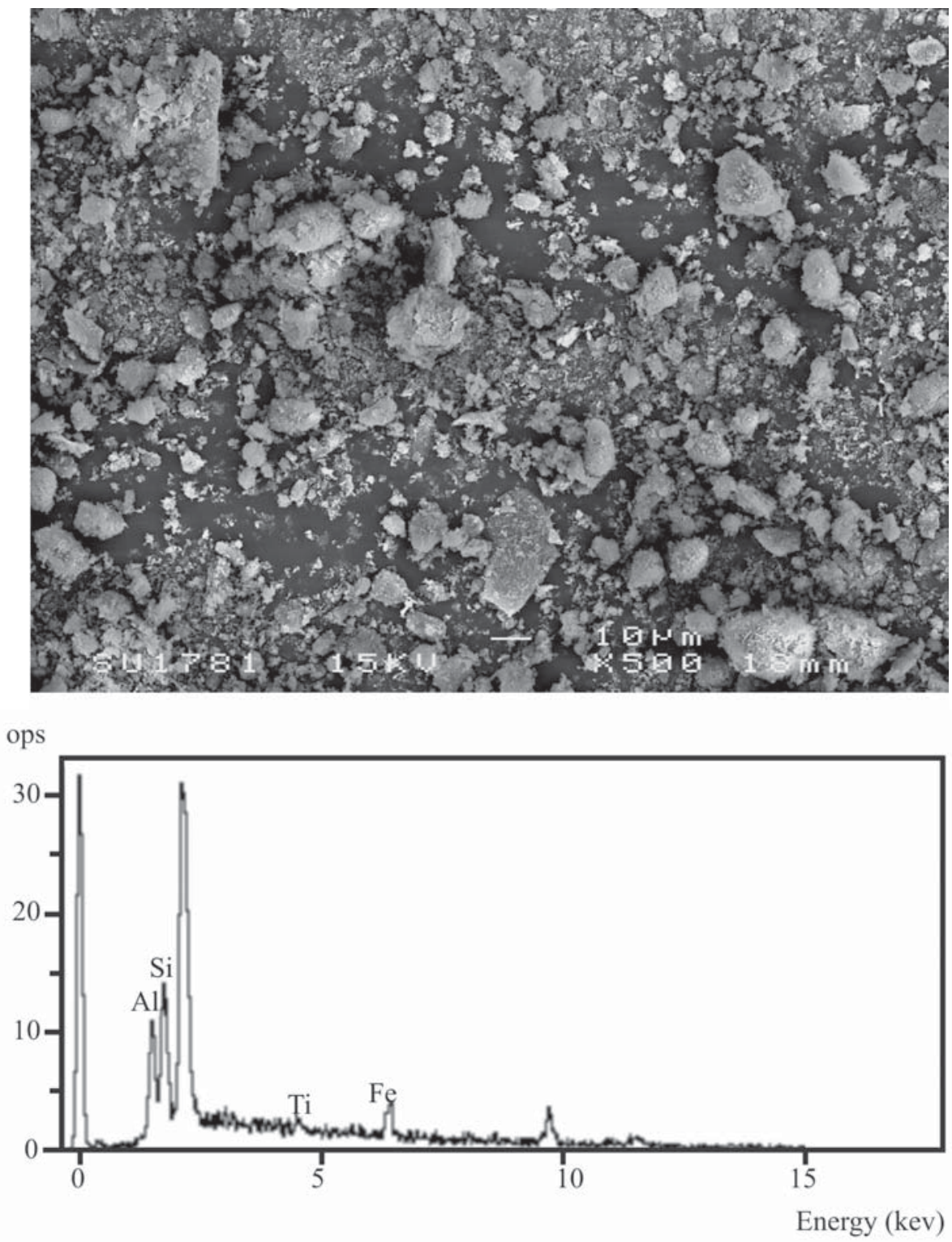

Figura 5: Aspectos morfológicos e mapeamento por EDS do resíduo de ETA.

[Figure 5: Overview of the waterworks waste sample and mapping by EDS.]

Tabela IV - Limites de Atterberg e massa específica real do resíduo.

[Table IV - Atterberg limits and real specific mass of the waste.].

\begin{tabular}{cccc}
\hline $\mathrm{LP}(\%)$ & $\mathrm{LL}(\%)$ & $\mathrm{IP}(\%)$ & $\mathrm{MER}\left(\mathrm{g} / \mathrm{cm}^{3}\right)$ \\
\hline 53 & 73 & 20 & 2,63 \\
\hline
\end{tabular}

cerâmicas argilosas deve-se fundamentalmente as forças de atração entre as partículas de argilominerais e a ação lubrificante da água existente entre as partículas lamelares. Além disso, a plasticidade é influenciada pelos seguintes fatores: mineralogia, granulometria, hábito lamelar dos minerais argilosos, carga elétrica dos cristais e natureza dos cátions de troca. Esta propriedade é de fundamental importância em cerâmica vermelha, visto que o principal método de conformação empregado é extrusão, que necessita de uma massa com consistência plástica. No presente trabalho a plasticidade do resíduo foi avaliada pelos limites de consistência de Atterberg [17]. O índice de plasticidade (IP) foi determinado por IP = LL - LP, onde LL (limite de liquidez) e LP (limite de plasticidade) são obtidos experimentalmente de acordo com procedimentos padronizados. Os resultados da Tabela IV mostram claramente que o sistema resíduo de ETA + água forma uma massa de consistência plástica, onde o valor de LP obtido foi de $53 \%$ e o IP foi de $20 \%$. Assim, o resíduo de ETA estudado pode ser classificado como 


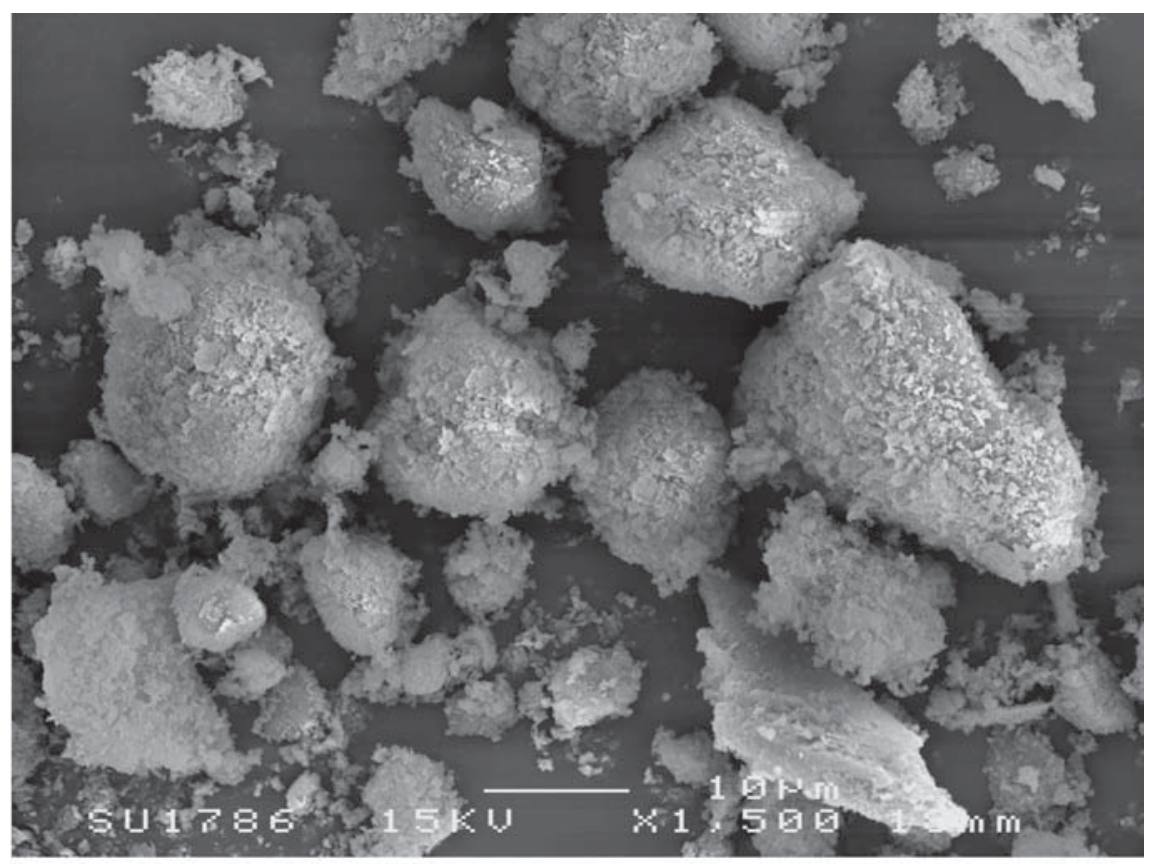

Figura 6: Detalhes morfológicos de placas aglomeradas do resíduo. [Figure 6: Morphological details of the waste agglomerate plates.]

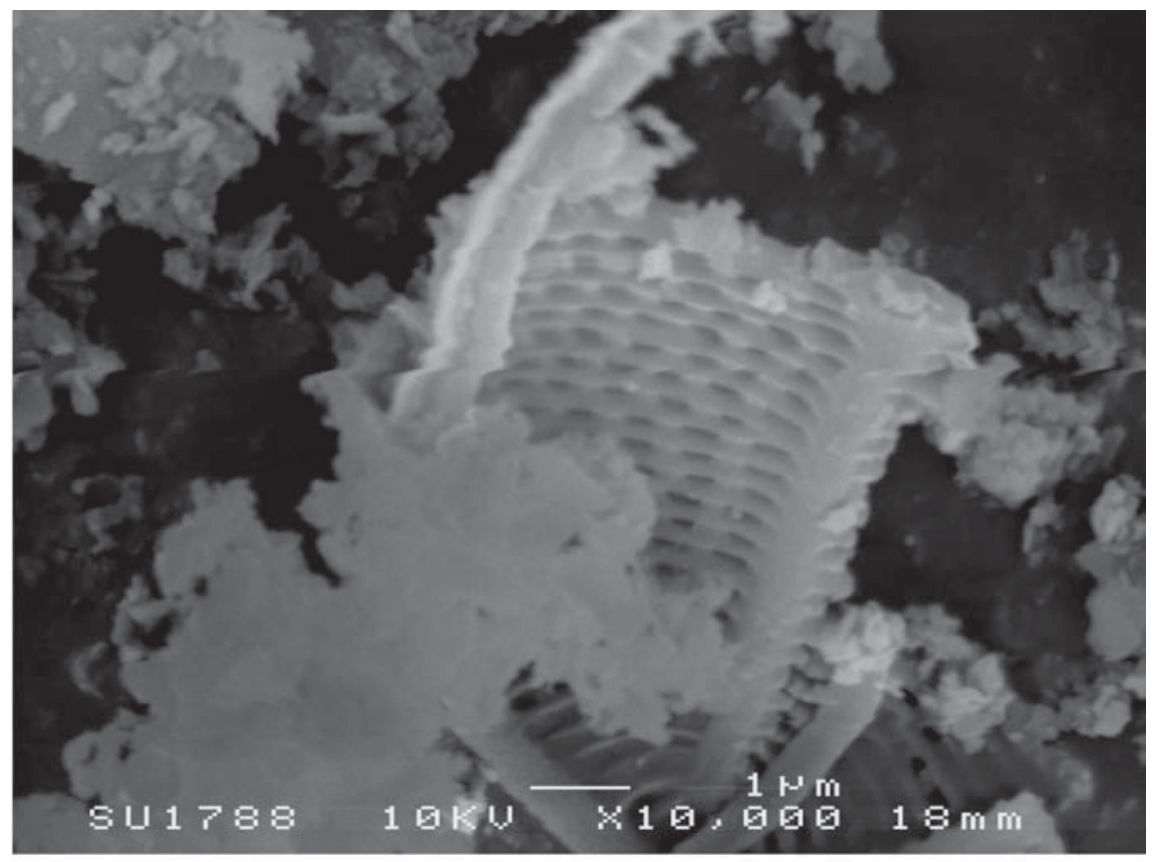

Figura 7: Fragmento de uma partícula do resíduo de ETA.

[Figure 7: Fragment of a particle of the waterworks waste.]

pertencente ao grupo de siltes inorgânicos de alta compressibilidade. $\mathrm{O}$ valor de IP indica que o resíduo de ETA pode ser usado em cerâmica vermelha, visto que as massas argilosas usadas em cerâmica vermelha devem apresentar valor de IP compreendidos entre $10<$ IP < 35\% [18]. No entanto, o resíduo de ETA também apresenta valor de limite de plasticidade (água de plasticidade) da ordem de 53\% muito acima da faixa recomendada para cerâmica vermelha (LP = 18 - 30\%). De forma que o resíduo de ETA estudado certamente apresentará dificuldade no processo de secagem, resultando em alta retração e defeitos nos corpos cerâmicos. Apesar dessa dificuldade, este resíduo pode ser utilizado quando adicionado 
em quantidades moderadas como componente de formulações argilosas apropriadas para cerâmica vermelha. De fato as formulações argilosas utilizadas na fabricação de cerâmica vermelha são do tipo monocomponente, somente argila, geralmente misturas entre duas ou mais argilas comuns. Nestas formulações busca-se obter condições apropriadas de plasticidade e fusibilidade, no sentido de propiciar trabalhabilidade e resistência mecânica após queima.

\section{CONCLUSÕES}

O resíduo proveniente da Estação de Tratamento de Águas (ETA) da região de Campos dos Goytacazes-RJ, constitui-se num material com grande potencial para aproveitamento na indústria de cerâmica vermelha. Este resíduo pode ser considerado como sendo uma formulação de massa argilosa natural.

O resíduo de ETA é um material plástico ( $(\mathrm{IP}=20 \%$ ) rico principalmente em $\mathrm{SiO}_{2}, \mathrm{Al}_{2} \mathrm{O}_{3}$ e $\mathrm{Fe}_{2} \mathrm{O}_{3}$. Do ponto de vista mineralógico, é constituído de caulinita, mica, sílica e gibsita, com predominância de caulinita. O resíduo apresenta morfologia irregular das partículas e larga distribuição de tamanho de partículas entre 1 até $425 \mu \mathrm{m}$. Além disso, o resíduo de ETA apresentou comportamento físico-químico e mineralógico semelhante ao de algumas argilas cauliníticas da região de Campos dos Goytacazes-RJ utilizadas para fabricação de cerâmica vermelha. No entanto, devido o alto valor do limite de plasticidade é recomendável que este resíduo seja usado em cerâmica vermelha somente como constituinte de formulações argilosas adicionado em quantidades adequadas. No sentido de concretizar este resultado estão em andamento, no Grupo de Pesquisa de Materiais Cerâmicos da UENF/LAMAV, trabalhos voltados para incorporação de resíduo de ETA da região de Campos dos Goytacazes, RJ, em cerâmica vermelha.

\section{AGRADECIMENTOS}

Os autores agradecem ao CNPq (Processo: 551478/20020) pelo apoio para a realização deste trabalho. Os autores agradecem também ao Consórcio Águas do Paraíba pelo fornecimento do resíduo (lodo) e ao M.Sc. Guilherme Parente Souza pelas análises por MEV/EDS.

\section{REFERÊNCIAS}

[1] E. M. S. Oliveira, Projeto de Tese de Doutorado, Universidade Estadual do Norte Fluminense, PPGECM-CCT, Campos dos Goytacazes, RJ (2003).

[2] http://www.tratamentodeagua.com.br/agua tratamentodeagua.php (2004).

[3] E. A. Domingues, R. Ullmann, App. Clay Sci. 11 (1996) 237-249.

[4] V. T. Bolaton, P. S. Gonçalves, L. M. Ferrer, Cerâmica Industrial 7, 6 (2002) 42-46.

[5] J. M. S. Moreira, M. N. Freire, J. N. F. Holanda, Cerâmica 49, 312 (2003) 262-267.

[6] T. Uslu, A. J. Arol, Waste Manag. 24 (2004) 217-220.

[7] R. R. Menezes, G. A. Neves, H. C. Ferreira, Rev. Bras. de Eng. Agr. e Amb. 6, 2 (2002) 303-313.

[8] I. S. S. Santos, M. V. V. Ramires, C. S. Kazmierczak, H. C. Silva, A. P. Kern, S. A. Camargo, Anais do $45^{\circ}$ Congresso Brasileiro de Cerâmica, Florianópolis, SC (2001) cdrom, p. 201-214.

[9] M. V. V. Ramires, I. S. S. Santos, C. S. Kazmierczak, H. C. Silva, A. P. Kern, S. A. Camargo, Anais do $45^{\circ}$ Congresso Brasileiro de Cerâmica, Florianópolis, SC (2001) cdrom, p. 301-308.

[10] G. P. Souza, R. Sanchez, J. N. F. Holanda, Cerâmica 48, 306 (2002) 102-107.

[11] J. N. F. Holanda, C. M. F. Vieira, Mundo Cerâmico 82 (2002) 29.

[12] P. S. Santos, Ciência e Tecnologia de Argilas, Vol. 1, 2a edição, Edgard Blücher Ltda, S. Paulo (1989).

[13] J. Alexandre, Tese de Doutorado, Universidade Estadual do Norte Fluminense, PPGCE-CCT, Campos dos Goytacazes, RJ (2000).

[14] J. S. Reed, Principles of Ceramic Processing, $2^{\text {nd }}$ Ed., John Wiley \& Sons, New York (1995).

[15] S. Pracidelli, F. G. Melchiades, Cerâmica Industrial 2, 01/02 (1997) 31-36.

[16] M. S. Andrade, N. M. M. Oliveira, M. A. C. Góes, S. C. A. França, Anais do $56^{\circ}$ Congresso Anual da ABM, Belo Horizonte, MG (2001) cdrom, p. 1019-1027.

[17] C. F. Gomes, Argilas - O que são e para que servem, Ed. Fundação Calouste Gulbenkian, Lisboa (1988).

[18] M. Dondi, Int. Ceramics J. (2003) 55-59.

(Rec. 21/05/04, Ac. 15/10/04) 